\title{
Lifestyle strategies for weight control: experience from the Finnish Diabetes Prevention Study
}

\author{
Jaana Lindström*, Markku Peltonen \& Jaakko Tuomilehto, for the Finnish \\ Diabetes Prevention Study Group \\ National Public Health Institute, Department of Epidemiology \& Health Promotion, Diabetes \& Genetic \\ Epidemiology Unit, Mannerheimintie 166, 00300 Helsinki, Finland
}

\begin{abstract}
Currently, in many European countries more than half the adult population is overweight; it has become 'abnormal' to be of 'normal weight'. The risk of type 2 diabetes, CVD, hypertension and certain forms of cancer increase with increasing weight. Biological evolution has produced body-fat-regulating mechanisms that are more powerful in protecting against weight loss than against weight gain. The current environment offers constant availability of affordable palatable energy-rich foods, with no need to consume the energy through physical activity. The 'obesogenic' environment is to some extent a political issue, but it has been shown that the healthcare system can also have a role in preventing obesity-related morbidity. The Finnish Diabetes Prevention Study was the first controlled randomised study to show that individualised lifestyle counselling of individuals with high risk of developing type 2 diabetes can influence diet, physical activity and body weight, and that type 2 diabetes can be prevented, or at least postponed. Most importantly, lifestyle changes do not have to be extreme. If the population would adopt a lifestyle in line with the official nutrition recommendations, the obesity and diabetes trend could at least be stabilised.
\end{abstract}

Obesity: Type 2 diabetes mellitus: Diet

The prevalence of both overweight and obesity is increasing dramatically in most populations worldwide. In many European countries more than half the adult population is overweight (International Obesity Task Force and European Association for the Study of Obesity, 2002).

The risk of type 2 diabetes, CVD, hypertension and certain forms of cancer increase with increasing weight. Thus, there is a large overlap between prevention of obesity and prevention of type 2 diabetes and other chronic diseases (World Health Organization, 2003). It has been estimated that the effect of obesity on morbidity is comparable in magnitude with that of smoking (Sturm \& Wells, 2001).

Obesity is the outcome of a positive energy balance over time. Obese individuals are, or have been at some stage, eating more energy than they need, and the excess energy has been stored as fat. This outcome does not exclude the fact that there are genetically-determined metabolic and/or behavioural differences between individuals who gain weight and those who do not (Perseghin, 2001). The massive increase in the prevalence of obesity during recent decades suggests that the explanation is in the interaction between the genetic background and the changing environment. Biological evolution has produced body-fat regulating mechanisms that are more powerful in promoting the search for food than in seeking to restrain energy intake; a reduction in body weight is strongly defended but weight gain is not (Schwartz et al. 2003). For the first time in human history there is constant availability of palatable foods for the majority of the population.

The choice of diet may depend on socio-economic factors. For individuals with a low income an unhealthy diet may actually be a rational economic decision, since sugar, refined grain and fat are the cheapest sources of dietary energy (Darmon et al. 2004). In Finnish men central obesity, measured by waist:hip ratio, has been shown to be more strongly determined by socio-economic and lifestyle factors than BMI (Marti et al. 1991). Even so, the increase in BMI and the prevalence of obesity has increased more 
in individuals in lower socio-economic groups (LahtiKoski et al. 2000).

Although physical activity level is also undoubtedly an important determinant of body weight, the focus of the present paper will be on dietary issues.

Several eating behaviours have been linked to weight gain. Meal patterns have been undergoing a transition; family meal times have given way to 'convenience eating' with almost constant opportunities for snacking and drinking. The association between snacking and obesity is controversial; both an inverse relationship (Drummond et al. 1998) and a predisposition to obesity (Berteus Forslund et al. 2002) have been reported. Consumption of a snack in a non-hungry state has been shown to have poor satiating efficiency, which may lead to excess energy intake (Marmonier et al. 2002). The role of hunger as a trigger to eat has been blurred. Food portion sizes have increased in the USA during the past decades both in (particularly fast-food) restaurants and in grocery stores (Nielsen \& Popkin, 2003), and there is no reason to think that the same pattern has not been repeated in European countries. It has been shown that the amount eaten correlates with the size of the portion (Diliberti et al. 2004). Ready-to-eat food items commonly marketed in super-size portions or economy packs usually are also high-fat and/or high-sugar low-fibre items and, therefore, induce low satiety and promote overconsumption of energy.

Nutrient factors that have been associated with obesity include fat, amount and type of carbohydrate, fibre and energy density of the diet, whereas protein has mostly been considered an 'innocent bystander'.

Although debate continues as to whether dietary fat is the primary determinant of excess body fat, a reduced-fat diet $(<30 \%$ energy from fat) is considered the conventional therapy for treating obesity. An ad libitum reducedfat diet without energy restriction has in several studies been shown to produce a moderate $(3-5 \mathrm{~kg})$ weight reduction (Astrup et al. 2002). Very-low-fat diets ( $\leq 15 \%$ energy from fat) have also been used, with weight reduction slightly higher (Lichtenstein \& Van Horn, 1998), but such low levels of fat intake are probably difficult to achieve for most individuals in a free-living setting.

During the past few years, low-carbohydrate weight-loss diets have challenged the conventional low-fat regimens and have attained extremely wide interest from the public and the media. The short-term weight loss achieved with low-carbohydrate diets has in several (Foster et al. 2003; Samaha et al. 2003; Buchholz \& Schoeller, 2004), but not all (Meckling et al. 2004), ad libitum studies been larger than the loss with low-fat diets. In a typical Western diet fat contributes $30-40 \%$ energy and carbohydrates $45-60 \%$ energy. A larger energy deficit after initiating a lowcarbohydrate diet may explain the better result for shortterm weight loss. Most of the dietary fat is normally ingested as 'hidden fat' incorporated in foods and ingredients such as cheese, milk products, meat, meat products and bakery products (e.g. biscuits, pastries and cakes), and only a small proportion is consumed as visible fat. In Finland the percentage of the total fat intake consumed as fat spreads and oils is 22 for men and 17 for women (Männistö et al. 2003). There are even products marketed as 'reduced fat', such as 'reduced-fat potato chips', which still contain $60 \%$ energy from fat. Thus, many individuals may mistakenly think that they are consuming a low-fat diet after eliminating visible fat. Carbohydrates, on the other hand, are normally eaten as bread, potatoes, rice, pasta, i.e. as a side dish, or as breakfast cereal. It can be assumed that in a free-living setting it is easier for most individuals to recognise and thus limit, at least for a short period, the intake of carbohydrate-containing items. If the energy intake is strictly and reliably controlled there seems to be no difference in the weight loss achieved with the two diet types (Golay et al. 1996).

The increase in carbohydrate intake to compensate for the decrease in fat intake during reduced-fat diets may exacerbate dyslipidaemia (Parks, 2001), which is one of the arguments used in favour of low-carbohydrate weightloss diets (Yancy et al. 2004). However, if consumption of sugar and refined grains as the source of carbohydrates is limited, the effect is attenuated (Fried \& Rao, 2003). Furthermore, the consumption of whole-grain products (Koh-Banerjee \& Rimm, 2003; Liu et al. 2003) and fibre (Ludwig et al. 1999) has been shown to be inversely associated with changes in body weight.

An increase in protein intake may increase patient satisfaction during consumption of a low-fat energyrestricted diet (Johnston et al. 2004) and has been shown to accelerate weight loss (Eisenstein et al. 2002) and prevent weight regain (Westerterp-Plantenga et al. 2004). It may also spare lean tissue and induce a greater loss of total and intra-abdominal fat (Parker et al. 2002; Farnsworth et al. 2003). Using an energy-controlled design, however, weight loss among insulin-resistant subjects has been found to be similar with high-protein (27\% energy) and lower-protein (16\% energy) diets (Luscombe et al. 2003). Furthermore, a large increase in protein intake has been associated with bone loss and impaired kidney function (Reddy et al. 2002).

The energy density of a diet is calculated as the energy per unit weight $(\mathrm{kJ} / \mathrm{g})$. Dietary energy density depends mainly on the fat and water content of the foods, and to lesser extent on the fibre content. Typical high-energydensity foods are those containing fat, added sugar and/or refined grains but not water. Low-energy-density foods are those with either a naturally-high water content (fruits, vegetables) or a high level of added water (soups etc.). It seems that individuals are only partly able to compensate for changes in the energy density of the diet by increasing or decreasing the total amount of food (Stubbs et al. 1998; Devitt \& Mattes, 2004).

Energy compensation following the consumption of energy-containing beverages may be more incomplete than that of solid food (World Health Organization, 2003), although this issue is controversial (Almiron-Roig et al. 2003). For some populations sugar-sweetened soft drinks form an important source of energy, which may in part be responsible for increasing body weight (Bray et al. 2004). If the increase in soft drink consumption is paralleled by a decrease in milk consumption, as can be assumed, and given that $\mathrm{Ca}$ has been shown to improve weight reduction, especially if obtained in the form of dairy products (Zemel et al. 2004), the synergistic effect may be even more harmful. 
Weight loss and negative energy balance per se produce substantial improvements in glycaemic control and lipoprotein metabolism. Regardless of the diet producing the weight loss, the weight will eventually either stabilise or start to increase. It is important that the diet advocated is also health promoting at that stage. The literature provides abundant evidence of the superiority of a diet containing large amounts of carbohydrates in the form of whole grains, fruits and vegetables, and a moderate amount of unsaturated fat in the form of vegetable oils, nuts, seeds and fish.

\section{The situation in Finland}

In Finland the mean BMI has increased by 0.6 and $0.8 \mathrm{~kg} / \mathrm{m}^{2}$ in young (25-34 years) men and women respectively, over the last 15 years (Lahti-Koski et al. 2000). In 2002 the age- and area-adjusted mean BMI among Finns aged $25-64$ years was $27.0 \mathrm{~kg} / \mathrm{m}^{2}$ for men and $25.9 \mathrm{~kg} / \mathrm{m}^{2}$ for women and $34 \%$ of men and $51 \%$ of women could be characterised as normal weight (BMI $<25 \mathrm{~kg} / \mathrm{m}^{2}$; Laatikainen et al. 2003).

Leisure-time exercise is a relatively common pastime among Finns. In $2002>50 \%$ of men and women reported that they exercise twice per week or more often $(\geq 30 \mathrm{~min}$ per occasion), and leisure-time exercise has become more popular during the past 30 years (Helakorpi et al. 2002). At the same time, however, commuting exercise (walking or bicycling to work) has decreased dramatically. According to Statistics Finland (2004), the number of cars per 1000 of the population was 256 in 1980 and had increased to 436, i.e. by $70 \%$, by 2003 . Finns $\geq 10$ years of age spend on average approximately $3 \mathrm{~h} / \mathrm{d}$ watching TV (Finnpanel Oy, 2004). Thus, the increase in recreational physical activity has probably been more than compensated by the decrease in lifestyle physical activity.

The Finnish diet changed most dramatically between 1970 and 1990. The reduction in intake of saturated fat from $21 \%$ energy to $14 \%$ energy was found to parallel the reduction in serum total cholesterol concentration seen in both men and women (Pietinen et al. 1996). The percentage energy from saturated fat is still higher than recommended levels, and during the past decade the progress achieved in reducing saturated fat intake and serum total cholesterol has stabilised.

The increase in BMI has been accompanied by an increase in type 2 diabetes. According to the drug reimbursement registry, there were 152584 patients with drug-treated diabetes in Finland at the end of year 2003, an increase of $5 \%$ from the previous year. The total number of patients with type 2 diabetes treated by diet is not known, but the estimated number of all known patients with type 2 diabetes is 200000 . The true prevalence is even higher, since up to $50 \%$ of patients with type 2 diabetes are unaware that they have the disease (DECODE Study Group, 2003).

Even though primary prevention of type 2 diabetes was proposed as early as 1921 (Joslin, 1921), only a limited number of studies have, until recently, attempted to assess the possibility of preventing type 2 diabetes by controlling its modifiable risk factors. The Finnish Diabetes Prevention Study (DPS; Eriksson et al. 1999; Tuomilehto et al.
2001) was the first controlled individually-randomised study to test the possibility of diabetes prevention by lifestyle intervention. The study population consisted of 522 middle-aged overweight volunteer men and women with impaired glucose tolerance and thus at high risk of developing type 2 diabetes. Two-thirds of the study subjects were women. At baseline the mean age was 55 years and the mean BMI was $31 \mathrm{~kg} / \mathrm{m}^{2}$.

The study subjects were randomly assigned either to the 'standard care' control group or the intensive lifestyle intervention group. At the start of the study the control group subjects were given general information by the study nutritionist and physician about how lifestyle factors affect glucose tolerance and diabetes risk. They had no individualised counselling. The intervention group had seven face-to-face dietary counselling sessions given by the study nutritionist during the first year of the intervention, and every 3 months thereafter (Lindström et al. 2003). All the sessions had a pre-planned topic (e.g. diabetes risk factors, saturated fat, fibre, physical activity, problem solving), but the discussions were personalised on the basis of specific individual needs. Printed material and leaflets were used to illustrate the message and to serve as a reminder at home. The goal was to equip the subjects with the necessary knowledge and skills, and to gradually achieve permanent behavioural changes. Some voluntary group sessions were also organised that included expert lectures, low-fat cooking sessions and visits to a local supermarket. The spouse's active role in making and maintaining lifestyle change was acknowledged and supported by inviting spouses to the counselling sessions.

The goals of the intervention were: weight reduction $\geqslant 5 \%$ from baseline weight; total fat intake $<30 \%$ energy intake; saturated fat intake $<10 \%$ energy intake, fibre intake $\geq 15 \mathrm{~g} / 4 \cdot 2$ MJ $(1000 \mathrm{kcal})$; moderate-to-vigorous exercise of $\geqslant 0.5 \mathrm{~h} / \mathrm{d}$. The study subjects were motivated to engage in any physical activity they enjoyed either as sports, recreational activities or incorporated into daily life activities and they were also offered an opportunity to use a gym free of charge.

Body weight is known to be an important risk factor for diabetes, and weight reduction was also the primary goal in the DPS. The dietary intervention was based on $3 \mathrm{~d}$ food diaries completed before the sessions. Reduction in energy intake was achieved by substituting high-energy-density food items with lower-energy foods and with a regular meal pattern, avoiding both frequent snacking and extended intervals between meals. The food plate model (National Nutrition Council, 1998) was used to estimate portion sizes. If half a normal-size plate is filled with raw or cooked vegetables, the amount of more-energy-dense food items is reduced in a natural way, without the need to weigh or measure the portions.

The intervention-group subjects were advised to eat lowfat milk products, meat and cheese, to use low-fat cooking methods and to cut down on high-fat cakes and pastries typically consumed with coffee or tea. These changes, which promote a reduction in saturated fat intake, will also produce a reduction in total fat. As unsaturated fat has been shown to be beneficial for glucose tolerance and the lipid profile, the use of rapeseed oil and margarine was 
recommended, as well as the regular consumption of fish. To increase fibre intake, whole-grain cereal products, especially rye bread, were recommended. Daily consumption of fruits, vegetables and berries was encouraged.

The main objective of the intervention was to achieve permanent lifestyle changes. The subjects in the intervention group were not put on a special diet, but were counselled to make gradual changes in their own diet and in their own lifestyle that they could maintain. The dietary recommendations used in the DPS were based on the recommendations of the National Nutrition Council (1998) for the whole Finnish population.

Dietary counselling was given by study nutritionists with an extensive knowledge of aspects of foods, nutrients and health. At each of the five study clinics the procedures were based on similar principles and sequence. The sessions each lasted for $30 \mathrm{~min}-1 \mathrm{~h}$. The programme was structured but flexible. Before the sessions the subjects completed a $3 \mathrm{~d}$ food diary, and they also kept an exercise diary. Body weight was measured at every visit. The continuous monitoring of the diet and physical activity during the trial allowed a very practical and individualised implementation of the intervention, in order to attempt to reach the goals. Probably because of this individualised approach the drop-out rate during the intervention period was relatively low $(8 \%)$, and was similar to that for the control group. The lifestyle intervention has been discontinued, but the follow-up of the study participants will be continued. Of the original study population $88 \%$ still attend for annual laboratory tests and other measurements.

At baseline the dietary intake ( $\%$ energy) of fat, protein and carbohydrate respectively was 36,18 and 44 for the intervention group and 37, 18 and 43 for the control group. Saturated fat provided $16 \%$ total energy in the intervention group and $17 \%$ total energy in the control group. Fibre intake was $12 \mathrm{~g} / 4 \cdot 2 \mathrm{MJ}(1000 \mathrm{kcal})$ in both groups. After the first year of the intervention there was an increase in the intake of carbohydrate (\% energy; $+3 \cdot 3 v .+1 \cdot 7)$ and fibre $(\mathrm{g} / 4 \cdot 2 \mathrm{MJ}(1000 \mathrm{kcal}) ;+2 \cdot 5 \mathrm{v} .+1)$, and a decrease in the intake $(\% \mathrm{E})$ of total fat $(-3 \cdot 4 v .-2 \cdot 1)$ and saturated fat $(-2 \cdot 7 v .-1 \cdot 2)$ that was higher for the intervention group compared with the control group. Also, moderate-tovigorous physical activity increased more for the intervention group than for the control group ( $+49 \mathrm{~min} /$ week v. $+14 \mathrm{~min} /$ week; Lindström et al. 2003).

The intervention group subjects lost more weight than the control group subjects. At year 1 weight reduction was 4.5 (SD 5.0) $\mathrm{kg}$ in the intervention group and 1.0 (SD 3.7) $\mathrm{kg}$ in the control group (Lindström et al. 2003). This magnitude of weight loss is typical of that seen in other studies in which a lifestyle approach for weight reduction has been used (Astrup et al. 2002). The fact that the subjects volunteering for the study were joining a diabetes prevention study, not a weight-loss programme, could have affected the result. There is some evidence that weight reduction and/or maintenance is more difficult for individuals with type 2 diabetes than for those with normal glucose tolerance, mainly as a result of a difference in dietary adherence (Guare et al. 1995), and the same may be true for individuals with milder defects in glucose tolerance. The addition of drug treatment has in a recent review

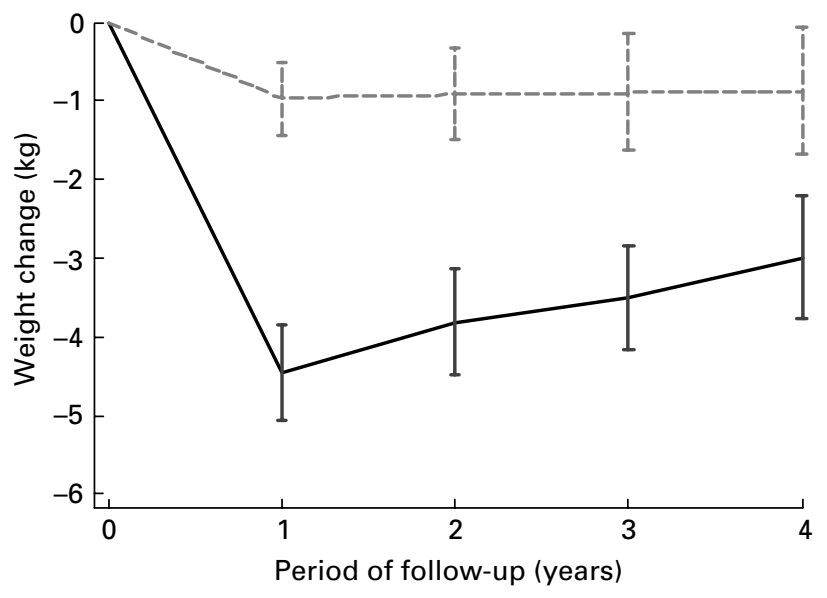

Fig. 1. Weight change during the 4-year follow-up period in the Finnish Diabetes Prevention Study, a controlled individually-randomised study testing the possibility of diabetes prevention by lifestyle intervention. The participants were 522 middle-aged overweight volunteer men and women with impaired glucose tolerance and thus at high risk of developing type 2 diabetes. Values are means and $95 \% \mathrm{Cl}$ represented by vertical bars. The no. of subjects in the control $(---)$ and intervention $(-)$ groups respectively were: baseline 265, 257; year 1 250, 256; year 2 226, 244; year 3203 , 231; year 4 170, 198.

(Padwal et al. 2003) been estimated to increase weight loss modestly $(2.7 \mathrm{~kg}$ for orlistat and $4.3 \mathrm{~kg}$ for sibutramine after 1 year of treatment with the drug compared with a placebo). The inclusion of orlistat (Torgerson et al. 2004) in an intensive lifestyle intervention has been found to markedly accelerate weight loss $(10.6 \mathrm{~kg} v .6 .2 \mathrm{~kg}$ after 1 year of treatment with orlistat $v$. a placebo combined with lifestyle intervention) and weight maintenance $(5 \cdot 8 \mathrm{~kg} v$. $3.0 \mathrm{~kg}$ after 4 years of treatment). In this study the drop-out rate was high, $48 \%$ in the orlistat group and $66 \%$ in the placebo group; however, only a minority of the subjects ( $8 \%$ in orlistat group and $4 \%$ in placebo group) withdrew because of adverse events. This high drop-out rate probably reflects, to some extent, the participants' disappointment with the treatment effect achieved with the drug. Weight loss achieved through lifestyle change has little if any side effects and may strengthen the subjects' perception of control over their life and health ('empowerment'), rather than relying on drugs.

Weight regain after an intensive weight-loss period is seen in practically all studies in which follow-up is arranged, regardless of the weight-loss regimen. Some regain also occurred in the DPS study after the first, most intensive, year of the intervention, but the difference between the groups remained throughout the study (Fig. 1).

The main results of the DPS study were published in 2001 and they were based on diabetes incidence by March 2000 (Tuomilehto et al. 2001), with a mean follow-up time of 3.2 years. By that time eighty-six subjects, twenty-seven in the intervention group and fifty-nine in the control group, had been diagnosed with diabetes. The cumulative incidence of type 2 diabetes was found to be $58 \%$ lower in the intervention group compared with the control group. The difference between the groups was substantial after 2 years 
Table 1. Diabetes risk by weight change in the Finnish Diabetes Prevention Study, a controlled individually-randomised study testing the possibility of diabetes prevention by lifestyle intervention*

\begin{tabular}{|c|c|c|c|c|c|c|}
\hline \multicolumn{3}{|c|}{ Weight change (\%) from baseline to year 1} & \multicolumn{2}{|c|}{ Model 1† } & \multicolumn{2}{|c|}{ Model $2 \dagger$} \\
\hline Quintile & Mean & Range & Hazard ratio & $95 \% \mathrm{Cl}$ & Hazard ratio & $95 \% \mathrm{Cl}$ \\
\hline 1 & $-10 \cdot 6$ & $-22 \cdot 0$ to $-7 \cdot 00$ & 0.35 & $0.17,0.69$ & 0.29 & $0.14,0.61$ \\
\hline 2 & $-4 \cdot 6$ & -6.98 to -3.00 & 0.51 & $0.27,0.94$ & 0.50 & $0.26,0.93$ \\
\hline 3 & $-2 \cdot 0$ & -2.99 to -1.00 & 0.90 & $0.50,1.60$ & $0 \cdot 80$ & $0.45,1.45$ \\
\hline 4 & 0.0 & -0.998 to -0.970 & \multicolumn{2}{|c|}{1} & \multicolumn{2}{|c|}{1} \\
\hline 5 & $3 \cdot 3$ & $1 \cdot 01$ to $12 \cdot 9$ & $1 \cdot 8$ & $1 \cdot 07,2 \cdot 91$ & $1 \cdot 49$ & $0 \cdot 89,2 \cdot 47$ \\
\hline Trend & & & \multicolumn{2}{|c|}{$P<0.0001$} & \multicolumn{2}{|c|}{$P<0.0001$} \\
\hline
\end{tabular}

${ }^{*}$ For details of procedures, see Tuomilehto et al. (2001).

†Model 1 is unadjusted and model 2 is adjusted for baseline weight, treatment group and sex.

of intervention. The study was interrupted prematurely, at the suggestion of the independent end-point committee, after this first interim analysis. The intervention was, however, continued until each subject's subsequent annual examination; it was considered unethical to cease the 3monthly dietary counselling and free access to the gym in the middle of the period. Furthermore, one centre continued the intervention until pre-planned termination at year 5. Thus, altogether 116 cases of diabetes were diagnosed before the intervention ended, forty-four in the intervention group and seventy-two in the control group.

The weight reduction during the first year of intervention was found to be a strong predictor of diabetes risk during the entire study (Table 1 ). The hazard ratio for the lowest weight-change quintile (weight reduction $>7 \%$ from baseline) compared with those whose weight did not change (quintile 4) was found to be $0 \cdot 35$, and was even lower after adjustment for baseline weight, treatment group and sex. An average weight reduction of $4.6 \%$ in the second quintile (weight reduction ranging from 3 to $7 \%$ ) was found to halve the diabetes risk compared with the quintile 4 . Thus, even a relatively modest weight reduction or even prevention of further weight gain may be of value when fighting the morbidity associated with obesity.

Interestingly, the effect of lifestyle intervention on diabetes risk seems to have been highest among subjects who were only moderately overweight at baseline (Table 2). Based on this result, lifestyle intervention would be the most cost-efficient when given at the early stage of overweight. In practice, most effort and money is usually spent on patients who are already quite obese.

The DPS has shown that with intensive lifestyle intervention it is possible to influence the lifestyle of high-risk individuals, and that type 2 diabetes can be prevented. Most importantly, lifestyle changes do not have to be extreme. If the Finnish population would adopt the lifestyle advocated according to the Finnish nutrition recommendations (National Nutrition Council, 1998), the diabetes trend could at least be stabilised. These findings have been confirmed by a similar American study (The Diabetes Prevention Program Research Group, 2002).

The cost of such lifestyle intervention, if provided in a healthcare setting, can be roughly estimated. The mostintensive first year includes approximately $5.5 \mathrm{~h}$ individual counselling (four $1 \mathrm{~h}$ visits and three $30 \mathrm{~min}$ visits), the second year $2.5 \mathrm{~h}$ and the third year $3.5 \mathrm{~h}$ (including $1 \mathrm{~h}$ annual
Table 2. Diabetes risk in the intensive lifestyle intervention group compared with the control group by baseline BMI in the Finnish Diabetes Prevention Study, a controlled individually-randomised study testing the possibility of diabetes prevention by lifestyle intervention*

\begin{tabular}{|c|c|c|c|c|}
\hline \multicolumn{3}{|c|}{ Baseline BMI $\left(\mathrm{kg} / \mathrm{m}^{2}\right)$} & \multirow[b]{2}{*}{ Hazard ratio } & \multirow[b]{2}{*}{$95 \% \mathrm{Cl}$} \\
\hline Tertile & Mean & Range & & \\
\hline 1 & $26 \cdot 9$ & $<28.78$ & 0.32 & $0 \cdot 12,0.80$ \\
\hline 2 & $30 \cdot 5$ & $28 \cdot 79-32 \cdot 29$ & 0.60 & $0.32,1 \cdot 12$ \\
\hline 3 & $36 \cdot 2$ & $>32 \cdot 3$ & 0.60 & $0.35,1.06$ \\
\hline
\end{tabular}

*For details of procedures, see Tuomilehto et al. (2001).

visits and $30 \mathrm{~min} 3$-monthly visits), altogether $11.5 \mathrm{~h}$ per subject per 3 years. Based on an average market price of $€ 60 / \mathrm{h}$, the cost of dietary counselling can be estimated to be $€ 690$ in 3 years (excluding the cost of calculating the dietary intake from food diaries). Compared with the estimated total costs of treating one patient with type 2 diabetes, without diabetic complications (€2600/year in 1997) or after complications appear (€11800/year; Kangas, 2002), the cost of lifestyle intervention can be considered reasonable. Naturally, the cost efficiency of prevention depends on how accurately subjects with the highest diabetes risk, who therefore would benefit the most from this kind of intensive intervention, can be identified. For this purpose, the Finnish Diabetes Risk Score (Lindström \& Tuomilehto, 2003) has recently been developed.

Based on the evidence derived from the DPS Finland has become the first country in the world to have developed a community-wide primary prevention programme for type 2 diabetes (Finnish Diabetes Association, 2003). In this programme the Finnish Diabetes Risk Score is used as a screening tool for high-risk subjects. Subjects identified as being at high risk for diabetes will be offered individual-oriented lifestyle intervention in the primary healthcare system. The lifestyle intervention offered is based on the methods used in the DPS, and accordingly modified to be feasible for use in the primary healthcare system. The intervention includes individual and group counselling on weight reduction, nutrition and physical activity. While it is now firmly established that type 2 diabetes is preventable in high-risk individuals using 
lifestyle intervention in a clinical trial setting, it remains to be seen how this strategy can be implemented at the population level, and what the effectiveness of such a strategy will be.

Lifestyle counselling is recognised as a cornerstone of the treatment of obesity and many chronic diseases, and in some form is routine in the healthcare system. Unfortunately, the lifestyle changes achieved have usually been disappointingly small. Empowerment is a word frequently used when talking about lifestyle counselling. However, its practical implementation is still mostly lacking. In the DPS the control-group subjects received a standard-care intervention, i.e. general instructions and some printed material. What they actually received is much more than routine care, because normally individuals with impaired glucose tolerance would not get any advice at all. Yet, there was a substantial difference between the outcomes for these two groups.

Behaviour change is a process, and it should not be assumed that major lifestyle changes can be achieved after one brief counselling session. Information must be personalised, and the implementation must be very practical; individuals eat food, not nutrients. Few individuals are willing and/or able to make extreme changes in their food intake pattern. Permanent lifestyle changes can only be achieved through small positive steps towards specific goals.

Obesity, and susceptibility to weight gain, is a chronic condition. Continuous care is required especially after intensive weight loss. For many individuals being on a diet is much easier than the free-living period following the diet period. It is probably not worthwhile to try to find a universal weight-control regimen that suits everyone. Group care with social support from other group members is effective with some individuals. Some individuals benefit from a very-low-energy-diet phase, but long-term results are likely to be disappointing if this phase is not accompanied by lifestyle counselling. In some studies the use of meal replacements has produced promising results (Heymsfield et al. 2003). Weight reduction with a lowcarbohydrate diet has also received much media attention and results from short-term studies are positive (Foster et al. 2003; Samaha et al. 2003). Cutting down sugar and refined grain products will improve many diets, but only time will tell what the net effect will be on body weight and metabolic variables if the deficit is compensated with meat, cheese and fatty milk products. The results from the DPS study support the officially recommended moderatefat high-carbohydrate high-fibre diet.

The obesogenic environment is to some extent a political issue. Walking and bicycling to work, school and shops should be made easy and appealing. Kindergartens, schools and staff canteens are in an excellent position to guide children, adolescents and adults to a healthy diet. In addition, there is a need and evidence-base for intensive lifestyle counselling. The staff working in the public health system must be provided with the necessary knowledge and skills to implement the intervention. The information given by different staff members must be reliable and uniform. Lifestyle goals must be realistic, practical and individualised.

\section{Acknowledgements}

We are indebted to DPS research team members for their proficient contribution in performing the study. The DPS study has received financial support from the Finnish Academy (grants 8473/2298, 40758/5767 and 38387/ 54175), the Ministry of Education, the Novo Nordisk Foundation, the Yrjö Jahnsson Foundation, the Juho Vainio Foundation and the Finnish Diabetes Research Foundation.

\section{References}

Almiron-Roig E, Chen Y \& Drewnowski A (2003) Liquid calories and the failure of satiety: how good is the evidence? Obesity Reviews 4, 201-212.

Astrup A, Buemann B, Flint A \& Raben A (2002) Low-fat diets and energy balance: how does the evidence stand in 2002? Proceedings of the Nutrition Society 61, 299-309.

Berteus Forslund H, Lindroos AK, Sjostrom L \& Lissner L (2002) Meal patterns and obesity in Swedish women-a simple instrument describing usual meal types, frequency and temporal distribution. European Journal of Clinical Nutrition 56, 740-747.

Bray GA, Nielsen SJ \& Popkin BM (2004) Consumption of highfructose corn syrup in beverages may play a role in the epidemic of obesity. American Journal of Clinical Nutrition 79, 537-543.

Buchholz AC \& Schoeller DA (2004) Is a calorie a calorie? American Journal of Clinical Nutrition 79, 899S-906S.

Darmon N, Briend A \& Drewnowski A (2004) Energy-dense diets are associated with lower diet costs: a community study of French adults. Public Health Nutrition 7, 21-27.

DECODE Study Group (2003) Age- and sex-specific prevalences of diabetes and impaired glucose regulation in 13 European cohorts. Diabetes Care 26, 61-69.

Devitt AA \& Mattes RD (2004) Effects of food unit size and energy density on intake in humans. Appetite 42, 213-220.

Diliberti N, Bordi PL, Conklin MT, Roe LS \& Rolls BJ (2004) Increased portion size leads to increased energy intake in a restaurant meal. Obesity Research 12, 562-568.

Drummond SE, Crombie NE, Cursiter MC \& Kirk TR (1998) Evidence that eating frequency is inversely related to body weight status in male, but not female, non-obese adults reporting valid dietary intakes. International Journal of Obesity and Related Metabolic Disorders 22, 105-112.

Eisenstein J, Roberts SB, Dallal G \& Saltzman E (2002) Highprotein weight-loss diets: are they safe and do they work? A review of the experimental and epidemiologic data. Nutrition Reviews 60, 189-200.

Eriksson $J$, Lindström $J$, Valle $T$, Aunola $S$, Hämäläinen $H$, Ilanne-Parikka P et al. (1999) Prevention of Type II diabetes in subjects with impaired glucose tolerance: the Diabetes Prevention Study (DPS) in Finland. Study design and 1-year interim report on the feasibility of the lifestyle intervention programme. Diabetologia 42, 793-801.

Farnsworth E, Luscombe ND, Noakes M, Wittert G, Argyiou E \& Clifton PM (2003) Effect of a high-protein, energy-restricted diet on body composition, glycemic control, and lipid concentrations in overweight and obese hyperinsulinemic men and women. American Journal of Clinical Nutrition 78, 31-39.

Finnish Diabetes Association (2003) Programme for the prevention of type 2 diabetes in Finland. http://www.diabetes.fi/ english/prevention/programme/index.html.

Foster GD, Wyatt HR, Hill JO, McGuckin BG, Brill C, Mohammed BS, Szapary PO, Rader DJ, Edman JS \& Klein S 
(2003) A randomized trial of a low-carbohydrate diet for obesity. New England Journal of Medicine 348, 2082-2090.

Finnpanel Oy (2004) Television audience measurement. TV people meter study. Finnpanel Oy - YLE audience research. http://www.finnpanel.fi/english.html

Fried SK \& Rao SP (2003) Sugars, hypertriglyceridemia, and cardiovascular disease. American Journal of Clinical Nutrition 78, 873S-880S.

Golay A, Allaz AF, Morel Y, de Tonnac N, Tankova S \& Reaven G (1996) Similar weight loss with low- or high-carbohydrate diets. American Journal of Clinical Nutrition 63, 174-178.

Guare JC, Wing RR \& Grant A (1995) Comparison of obese NIDDM and nondiabetic women: short- and long-term weight loss. Obesity Research 3, 329-335.

Helakorpi S, Patja K, Prättälä R \& Aro A (2002) Suomalaison aikuisväestön turveyskäyttäybyminen ja terveys, kevät 2002 (Health Behaviour and Health among Finnish adult population, Spring 2002) Publications of the National Public Health Institute Series B12/2002. Helsinki, Finland: National Public Health Institute.

Heymsfield SB, van Mierlo CA, van der Knaap HC, Heo M \& Frier HI (2003) Weight management using a meal replacement strategy: meta and pooling analysis from six studies. International Journal of Obesity and Related Metabolic Disorders 27, 537-549.

International Obesity Task Force and European Association for the Study of Obesity (2002) Obesity in Europe. The Case for Action. London: International Association for the Study of Obesity.

Johnston CS, Tjonn SL \& Swan PD (2004) High-protein, lowfat diets are effective for weight loss and favorably alter biomarkers in healthy adults. Journal of Nutrition 134, 586-591.

Joslin E (1921) The prevention of diabetes mellitus. Journal of the American Medical Association 76, 79-84.

Kangas T (2002) Diabeetikkojen Terveyspalvelut ja Niiden Kustannukset. Helsinkiläisten Diabeetikkojen Verrokkikontrolloitu Poikkileikkaustutkimus (Structure and Costs of Health Care of Diabetic Patients in Helsinki. A Controlled Crosssectional Study). Helsinki, Finland: KELA.

Koh-Banerjee P \& Rimm EB (2003) Whole grain consumption and weight gain: a review of the epidemiological evidence, potential mechanisms and opportunities for future research. Proceedings of the Nutrition Society 62, 25-29.

Laatikainen T, Tapanainen H, Alfthan G, Salminen I, Sundvall J, Leiviskä J, Harald K, Jousilahti P, Salomaa V \& Vartiainen E (2003) Finriski 2002. Tutkimuksen Toteutus ja Tulokset 1. Perusraportti (The National FINRISK Study. The 2002 Survey Report 1). Helsinki, Finland: National Public Health Institute.

Lahti-Koski M, Vartiainen E, Männistö S \& Pietinen P (2000) Age, education and occupation as determinants of trends in body mass index in Finland from 1982 to 1997. International Journal of Obesity and Related Metabolic Disorders 24, 1669-1676.

Lichtenstein AH \& Van Horn L (1998) Very low fat diets. Circulation 98, 935-939.

Lindström J, Louheranta A, Mannelin M, Rastas M, Salminen V, Eriksson J, Uusitupa M \& Tuomilehto J (2003) The Finnish Diabetes Prevention Study (DPS): Lifestyle intervention and 3 -year results on diet and physical activity. Diabetes Care 26, $3230-3236$

Lindström J \& Tuomilehto J (2003) The Diabetes Risk Score: A practical tool to predict type 2 diabetes risk. Diabetes Care 26, 725-731.

Liu S, Willett WC, Manson JE, Hu FB, Rosner B \& Colditz G (2003) Relation between changes in intakes of dietary fiber and grain products and changes in weight and development of obesity among middle-aged women. American Journal of Clinical Nutrition 78, 920-927.

Ludwig DS, Pereira MA, Kroenke CH, Hilner JE, Van Horn L, Slattery ML \& Jacobs DR (1999) Dietary fiber, weight gain, and cardiovascular disease risk factors in young adults. Journal of the American Medical Association 282, 1539-1546.

Luscombe ND, Clifton PM, Noakes M, Farnsworth E \& Wittert $\mathrm{G}$ (2003) Effect of a high-protein, energy-restricted diet on weight loss and energy expenditure after weight stabilization in hyperinsulinemic subjects. International Journal of Obesity and Related Metabolic Disorders 27, 582-590.

Männistö S, Ovaskainen M \& Valsta L (2003) Finravinto 2002 Tutkimus (The National FINDIET 2002 Study). Publications of the National Public Health Institute Series B3/2003. Helsinki, Finland: National Public Health Institute.

Marmonier C, Chapelot D, Fantino M \& Louis-Sylvestre J (2002) Snacks consumed in a nonhungry state have poor satiating efficiency: influence of snack composition on substrate utilization and hunger. American Journal of Clinical Nutrition 76, 518-528.

Marti B, Tuomilehto J, Salomaa V, Kartovaara L, Korhonen HJ \& Pietinen P (1991) Body fat distribution in the Finnish population: environmental determinants and predictive power for cardiovascular risk factor levels. Journal of Epidemiology and Community Health 45, 131-137.

Meckling KA, O'Sullivan C \& Saari D (2004) Comparison of a low-fat diet to a low-carbohydrate diet on weight loss, body composition, and risk factors for diabetes and cardiovascular disease in free-living, overweight men and women. Journal of Clinical Endocrinology and Metabolism 89, 2717-2723.

National Nutrition Council (1998) Finnish Nutrition Recommendations. Helsinki, Finland: Ministry of Agriculture and Forestry.

Nielsen SJ \& Popkin BM (2003) Patterns and trends in food portion sizes, 1977-1998. Journal of the American Medical Association 289, 450-453.

Padwal R, Li SK \& Lau DC (2003) Long-term pharmacotherapy for overweight and obesity: a systematic review and metaanalysis of randomized controlled trials. International Journal of Obesity and Related Metabolic Disorders 27, 1437-1446.

Parker B, Noakes M, Luscombe N \& Clifton P (2002) Effect of a high-protein, high-monounsaturated fat weight loss diet on glycemic control and lipid levels in type 2 diabetes. Diabetes Care 25, 425-430.

Parks EJ (2001) Effect of dietary carbohydrate on triglyceride metabolism in humans. Journal of Nutrition 131, 2772S2774S.

Perseghin G (2001) Pathogenesis of obesity and diabetes mellitus: insights provided by indirect calorimetry in humans. Acta Diabetologica 38, 7-21.

Pietinen P, Vartiainen E, Seppänen R, Aro A \& Puska P (1996) Changes in diet in Finland from 1972 to 1992: impact on coronary heart disease risk. Preventive Medicine 25, 243-250.

Reddy ST, Wang CY, Sakhaee K, Brinkley L \& Pak CY (2002) Effect of low-carbohydrate high-protein diets on acid-base balance, stone-forming propensity, and calcium metabolism. American Journal of Kidney Diseases 40, 265-274.

Samaha FF, Iqbal N, Seshadri P, Chicano KL, Daily DA, McGrory J, Williams T, Williams M, Gracely EJ \& Stern L (2003) A low-carbohydrate as compared with a low-fat diet in severe obesity. New England Journal of Medicine 348, 2074-2081.

Schwartz MW, Woods SC, Seeley RJ, Barsh GS, Baskin DG \& Leibel RL (2003) Is the energy homeostasis system inherently biased toward weight gain? Diabetes 52, 232-238.

Stubbs RJ, Johnstone AM, O'Reilly LM, Barton K \& Reid C (1998) The effect of covertly manipulating the energy density 
of mixed diets on ad libitum food intake in 'pseudo free-living' humans. International Journal of Obesity and Related Metabolic Disorders 22, 980-987.

Statistics Finland (2004) Transport and tourism statistics. http:// www.stat.fi/tk/tp/tasku/taskus_liikenne.html

Sturm R \& Wells KB (2001) Does obesity contribute as much to morbidity as poverty or smoking? Public Health 115, 229-235.

The Diabetes Prevention Program Research Group (2002) Reduction in the incidence of type 2 diabetes with lifestyle intervention or metformin. New England Journal of Medicine 346, 393-403.

Torgerson JS, Hauptman J, Boldrin MN \& Sjostrom L (2004) XENical in the Prevention of Diabetes in Obese Subjects (XENDOS) Study: A randomized study of orlistat as an adjunct to lifestyle changes for the prevention of type 2 diabetes in obese patients. Diabetes Care 27, 155-161.

Tuomilehto J, Lindström J, Eriksson JG, Valle TT, Hämäläinen $\mathrm{H}$, Ilanne-Parikka $\mathrm{P}$, Keinänen-Kiukaanniemi $\mathrm{S}$, Laakso M, Louheranta A, Rastas M, Salminen V \& Uusitupa M (2001) Prevention of type 2 diabetes mellitus by changes in lifestyle among subjects with impaired glucose tolerance. New England Journal of Medicine 344, $1343-1350$.

Westerterp-Plantenga MS, Lejeune MP, Nijs I, van Ooijen M \& Kovacs EM (2004) High protein intake sustains weight maintenance after body weight loss in humans. International Journal of Obesity and Related Metabolic Disorders 28, 57-64.

World Health Organization (2003) Diet, Nutrition and the Prevention of Chronic Diseases. Report of a Joint FAO/WHO Consultation. Geneva: WHO.

Yancy WS Jr, Olsen MK, Guyton JR, Bakst RP \& Westman EC (2004) A low-carbohydrate, ketogenic diet versus a low-fat diet to treat obesity and hyperlipidemia: a randomized, controlled trial. Annals of Internal Medicine 140, 769-777.

Zemel MB, Thompson W, Milstead A, Morris K \& Campbell P (2004) Calcium and dairy acceleration of weight and fat loss during energy restriction in obese adults. Obesity Research $\mathbf{1 2}$ $582-590$. 